\title{
Turbidity removal by conventional and ballasted coagulation with natural coagulants
}

\author{
V.T. Gaikwad ${ }^{1}$ (1) G. R. Munavalli²
}

Received: 19 November 2018 / Accepted: 24 June 2019 / Published online: 5 July 2019

(c) The Author(s) 2019

\begin{abstract}
Kernel of Moringa oleifera and Strychnos potatorum (Nirmali) seeds has the potential for turbidity removal. However, potential of seed kernel naturally dried in trees and that of sun-dried and oven-dried seeds and other parts, such as coat and wing of Moringa oleifera, has not been explored. In the present study, various forms of kernel and parts of Moringa oleifera seed were used to assess the removal of turbidity aided with/without coagulant aid and ballasting agent. Low ( $<12$ NTU), medium $(>13<=24 \mathrm{NTU})$ and high turbidity $(>=25<=35 \mathrm{NTU})$ water samples were used in the present study. Micro-sand and powdered activated carbon (PAC) were used as ballasting agents along with Aloe Vera as a coagulant aid/natural polymer. The kernel from seeds naturally dried in Moringa oleifera tree was found to possess more coagulant property. The optimum dose of Moringa oleifera for medium and high turbidity was found to be $50 \mathrm{mg} / \mathrm{L}$ and $100 \mathrm{mg} / \mathrm{L}$, respectively, with turbidity removal of $90.46 \%$ and $88.57 \%$. The optimum dose of Strychnos potatorum was $0.2 \mathrm{mg} / \mathrm{L}, 0.6 \mathrm{mg} / \mathrm{L}$, and $0.8 \mathrm{mg} / \mathrm{L}$ for low, medium and high turbidity, with turbidity removal as $71.42,64.28$ and $57.14 \%$, respectively. Aloe Vera acts as a coagulant aid with the natural coagulants and increases turbidity removal. Ballasting agents micro-sand and PAC, with Aloe Vera and coagulants, increase turbidity removal and reduce the settling time.
\end{abstract}

Keywords Aloe vera $\cdot$ Ballasting $\cdot$ Micro sand $\cdot$ Moringa oleifera $\cdot$ Strychnos potatorum $\cdot$ Turbidity

\section{Introduction}

Surface water is the primary source of potable water supply systems in most of the cases. These sources are largely contaminated by surface runoff and wastewater. The turbidity imparted thereby necessitates treatment for its removal before supplied to consumers for potable use. Turbidity is a significant physical water quality parameter and largely contributed by non-settleable solids. Normally, municipal water supply and treatment systems have centralized water treatment system wherein the concept is to treat and supply. Typically, in such systems the raw water is treated with physical and chemical treatment viz. coagulation, flocculation,

V. T. Gaikwad

vitthaltgaikwad@gmail.com

G. R. Munavalli

guru.munavalli@walchandsangli.ac.in

1 Department of Civil Engineering, P.V.P.I.T., Budhgaon, Sangli 416304, India

2 Department of Civil Engineering, Walchand College of Engineering, Sangli 416416, India settling and filtration for turbidity removal. The centralized treat and supply systems have several limitations such as requirement of chemicals, sludge disposal problems, contamination/deterioration of water quality during distribution and requirement of energy-intensive mechanized systems. In this context, decentralized water treatment system (DWTS) based on the concept of supply and treat implemented through point of use (PoU) purifiers is a feasible option which caters to overcome the above limitations. PoU purifiers available in the market are more suitable for urban population in developing countries like India and are not cost-effective in terms of capital and recurring cost. However, there is a need to develop economically feasible technologies for turbidity removal in PoU purifiers which are more appropriate for rural population. The locally available plant materials, which have a potential to be used as a coagulant/coagulant aid, are useful to develop such technologies. The ballasted flocculation/coagulation which enhances turbidity removal efficiency can also be a part of PoU purifier. The plant-derived natural coagulants could create economic benefits, as cultivation of plants as a means of revenue 
generation would also provide new job opportunities for the local population.

Bhole and Shrivastava (1983), Raghuwanshi et al. (2002), and Swati and Govindan (2005) used Strychnos potatorum (Nirmali seed) as a coagulant/coagulant aid and reported their suitability for turbidity removal. Jahn (1986) studied the coagulant potential of different species of Moringa oleifera and reported that out of 14 species of Moringacea, only Moringa oleifera and Moringa stenopetala possess efficient coagulation properties. Muyibi and Evison (1995) carried out the optimization studies using Moringa oleifera for low, medium and high turbidity water and reported residual turbidity less than 10 NTU in all cases. Okuda et al. (2001) studied coagulation mechanism of salt solution-extracted active component in Moringa oleifera seeds. Narasiah et al. (2002) conducted a study on turbidity removal in synthetic turbid water under laboratory-controlled conditions using natural coagulant-flocculant Moringa oleifera seeds from Burandi, Central Africa, and from Mahajanga, Madagascar. The seeds from Burandi were found to be of superior quality than those of Madagascar. Other studies conducted to remove turbidity using Moringa oleifera include Raghuwanshi et al. (2002), Sudhirkumar et al. (2010) and Sarpong and Richerdson (2010). Montakhab and Gazali (2010) used Moringa oleifera seed powder extracted with $\mathrm{NaNO}_{3}$. Dalen et al. (2011) studied the synergy between Moringa oleifera seed powder and alum in the purification of water. Gulmire and Munavalli (2017) used Aloe Vera as a coagulant/coagulant aid for turbidity removal and found 60-65\% removal efficiency raw water turbidity of 20-30 NTU.

Shahnawaz et al. (2002) carried out the bench- and pilot-scale studies using sand-ballasted flocculation and conventional coagulation and reported the effectiveness of sand as ballasting agent. Other studies on ballasted flocculation include Young and Edwards (2003) (factors affecting ballasted flocculation), Blumenschein et al. (2004) (performance of sand-ballasted high-rate clarification), and Ghanem et al. (2007) mode of transport of ballasting agent from bulk liquid).

The literature review shows that the kernel extracts of Moringa oleifera and Strychnos potatorum and gel of Aloe Vera have potential for their usage as coagulant for turbidity removal. But the potential of various forms of kernel (naturally and artificially dried) and parts of (seed coat/wings/pod) of Moringa oleifera seed has not been assessed for turbidity removal. The use of Aloe vera as a coagulant aid along with Moringa oleifera and Strychnos potatorum is also not studied. It can also be seen from the literature review that sand-ballasted flocculation was used effectively along with Alum and synthetic polymer as a coagulant for turbidity removal. In this context, the present study contributes to existing knowledge on use of natural coagulants for turbidity removal in the following ways:

Coagulation study with various forms of kernel and parts of Moringa oleifera seed.

1. Sand-ballasted flocculation with natural plant-derived coagulants (Moringa oleifera and Strychnos potatorum) and Aloe Vera as a binder (polymer).

2. Use of powdered activated carbon as a ballasting agent in ballasted coagulation study.

\section{Materials and methods}

\section{Preparation of turbid water}

River water was used in the study. The composition of a typical raw water sample collected from river has: turbidity 5-50 NTU, hardness $120-140 \mathrm{mg} / \mathrm{L}$ as $\mathrm{CaCO}_{3}$, $\mathrm{pH} 7-7.6$, TDS $300-400 \mathrm{mg} / \mathrm{L}$ and alkalinity $200 \mathrm{mg} / \mathrm{L}$ as $\mathrm{CaCO}_{3}$. The turbidity of settled raw water collected was less than 35 NTU. Low ( $<12$ NTU), medium ( $>13<=24$ NTU) and high turbidity ( $>=25<=35 \mathrm{NTU}$ ) water samples were used in the present study. The water sample with required value of turbidity for the coagulation study was prepared by either remixing with alluvial soil $(<75 \mu \mathrm{m})$ or by diluting it with less turbid settled water. Series of such samples were prepared, and turbidity was ascertained through measurement by nephelo-turbidity meter. Thus, in the present study, the water samples used were contributed by suspended solids normally found in river water.

\section{Moringa oleifera seeds}

The pods of Moringa oleifera were collected from various locations in Sangli district, India (M.S.). These collected pods included matured green/partially dried and completely dried on the tree. The kernel of seed from completely dried pod collected from Moringa oleifera tree is referred as naturally dried seed kernel in the study. The coat of such seeds was also used in coagulation study. The matured green/partially dried pods were either sun-dried or oven-dried. One week period was used for sun drying. Temperature of $103{ }^{\circ} \mathrm{C}$ for $2 \mathrm{~h}$ was used for oven drying. The kernel of seed from pods which were sun-dried was referred as sun-dried seed kernel, and the kernel of Moringa oleifera seeds which were used oven-dried was referred as oven-dried seed kernel in the present study.

The kernel of seeds was used to prepare extract. The dried kernels were crushed and ground in domestic mixer to lowest possible size. One gram of pulverized kernel was mixed with $100 \mathrm{~mL}$ of distilled water, and the contents were 
blended in the mixer at highest possible speed for $60 \mathrm{~s}$. The suspension was filtered and used as $1 \%$ stock solution. The fresh stock solution was prepared as and when required fresh for use. An extract of coat of naturally dried Moringa oleifera seeds was also prepared similarly.

\section{Strychnos potatorum (Nirmali)}

Strychnos potatorum seeds were procured from the market. The coating of seed was removed, and kernel was pulverized to powder. A stock solution of $0.1 \%$ strength was prepared following same procedure as discussed previously for Moringa oleifera seed kernel.

\section{Aloe Vera}

The leaves of locally available Aloe Vera plant were collected. The outer skin of the leaves was removed, and pulp/ gel was separated. The gel was blended in a mixer to get uniform liquefied paste. One gram of such fresh liquefied paste was mixed in $100 \mathrm{~mL}$ of distilled water and blended in mixer at more than $100 \mathrm{rpm}$ to get $1 \%$ solution.

\section{Ballasting agents}

Standard sand (quality defined by Bureau of Indian Standards IS650, grade-III) was used in the study as a ballasting agent. The size of sand between 90 and $150 \mu \mathrm{m}$ and specific gravity of 2.65 was used. Powdered activated carbon (PAC) manufactured by Thermo Fisher Scientific India Pvt. Ltd., having size $75-90 \mu \mathrm{m}$ and density of $360 \mathrm{~kg} / \mathrm{m}^{3}$ was used as another ballasting agent alternative to sand.

\section{Planning of experiments}

The experiments were planned (1) to analyze raw and treated turbid water, (2) to carry out coagulation studies with Moringa oleifera and Strychnos potatorum as coagulant with and without Aloe Vera as coagulant aid, and (3) to conduct ballasted flocculation studies with clean standard sand and PAC. All the experiments of conventional and ballasted flocculation were performed with a standard jar test apparatus. The range of coagulant dose (10-100 mg/L for Moringa oleifera and $0.20-1 \mathrm{mg} / \mathrm{L}$ for Strychnos potatorum) and dose of coagulant aid Aloe Vera $(10-100 \mathrm{mg} / \mathrm{L})$ was used. These dosages were identified through trials and by referring the literature. The optimum $\mathrm{pH}$ was also determined for effective removal of turbidity. The coagulation studies were used as a reference to compare the results with that of ballasted flocculation. The maximum dosage of standard micro-sand and PAC used was $4 \mathrm{~g} / \mathrm{L}$ and $0.50 \mathrm{~g} / \mathrm{L}$, respectively. In the ballasted flocculation study, optimum dose of Aloe Vera as a polymer was determined followed by determination of optimum dose of coagulant for particular ballasting agent dose. Therefore, series of experiments using Aloe Vera were planned. Five experiments were conducted for each dosage to assess the effectiveness of treatment, and average of these results was taken for discussions.

\section{Experimental procedure}

The jar test procedure was adopted to assess the effectiveness of Moringa oleifera and Strychnos potatorum with and without Aloe Vera as coagulant aid. The jar test procedure was referred to Bell-Ajy et al. (2000) and it consisted of rapid stirring at $120 \mathrm{rpm}$ for $1 \mathrm{~min}$, followed by a slow stirring at $40 \mathrm{rpm}$ for $10 \mathrm{~min}$ and at $20 \mathrm{rpm}$ for $10 \mathrm{~min}$, consecutively; and finally settling for $30 \mathrm{~min}$ for a volume of 1 L synthetic sample.

The ballasted flocculation was carried out by initiating stirring, coagulating at $300 \mathrm{rpm}$ for $2 \mathrm{~min}$, injecting Aloe Vera (polymer) followed by $1 \mathrm{~min}$ stirring at $300 \mathrm{rpm}$, injecting appropriate dosage of ballasting agent, followed by stirring at $200 \mathrm{rpm}$ for $2 \mathrm{~min}$, and settling for $30 \mathrm{~min}$. The settled sample was pipetted out a little $(10 \mathrm{~mm})$ below the surface of water for analysis in each of these jar test procedures. Raw and residual turbidity were measured.

All the procedures for analyzed parameters viz. $\mathrm{pH}$, turbidity, alkalinity, and TDS were referred to Standard Methods for the Examinations of Water and Wastewater (1998). $\mathrm{pH}$ value of the samples was determined by $\mathrm{pH}$ meter. Turbidity was measured using a Hach 2100 series Nephelo-turbidity meter. The specific gravity of sand was determined by Pycnometer method.

\section{Result and discussion}

\section{Effectiveness of kernel and coat of Moringa oleifera seeds for turbidity removal}

Figure 1 shows the efficiency of turbidity removal by seed kernel (naturally dried, sun-dried and oven-dried) and coat of naturally dried seed. The results show that the coat of seed is relatively less efficient and naturally dried seed is more efficient in turbidity removal. Removal to an extent of $36 \%$ is possible with dosage of $10 \mathrm{mg}$ coat of seed/L indicating that it has also some turbidity removal potential. This observation is significant as it can be used as coagulant aid due to its larger availability compared to kernel. However, naturally dried seeds can remove turbidity by $90 \%$ at a coagulant dosage of $50 \mathrm{mg} / \mathrm{L}$. The comparison of turbidity 
Fig. 1 Effect of coat and seed kernel of Moringa oleifera on turbidity removal

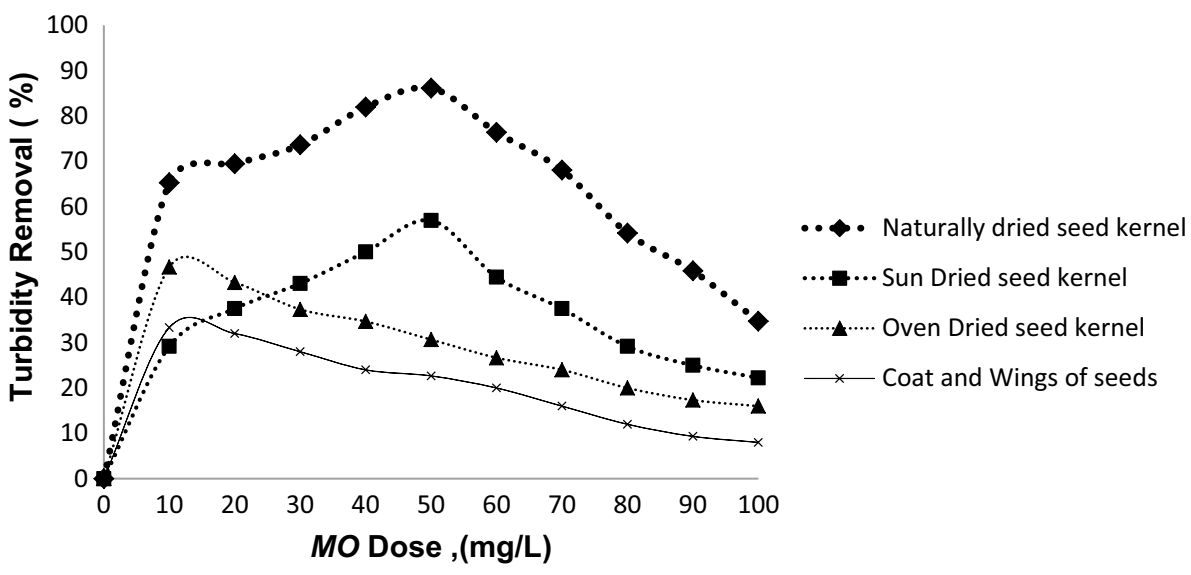

removal by sun-dried and oven-dried shows that sun-dried seeds are more efficient.

The predominant mechanism for coagulation is adsorption between coagulation active components in Moringa oleifera and particles of suspension to permit inter-particle bridging, and is not charge neutralization (Muyibi and Evison 1995; Ali et al. 2016). The efficiency of adsorption depends on the adsorbent surface area, surface morphology, pore size distribution, polarity and functional groups attached to the adsorbent surface (Ali et al. 2016). This indicates that naturally dried Moringa oleifera seed extract contains more active ingredients with more surface area available for adsorption and inter-particulate bridging (Joseane et al. 2013). The morphological characteristics of the powder of above materials used in the study were carried out through scanning electron microscope (SEM) with different levels of magnification to ascertain extent of porous nature of materials. Figure 2 shows the results of SEM study.

It can be seen that the naturally dried Moringa oleifera seed kernel is amorphous in nature with hips of fine particles which indicate availability of more surface area for adsorption. Sun-dried seed has agglomerated grains resulting in a flocculent structure. Oven-dried seed kernel is
Fig. 2 Results of SEM study for a naturally dried; $\mathbf{b}$ sun-dried; $\mathbf{c}$ oven-dried; and $\mathbf{d}$ coat (a)

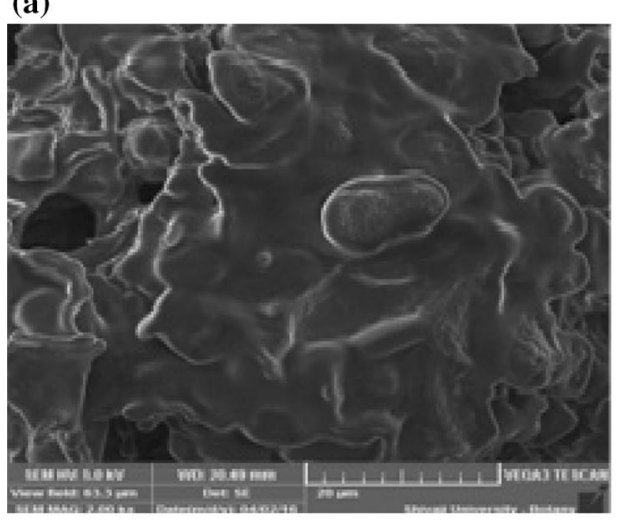

(c)

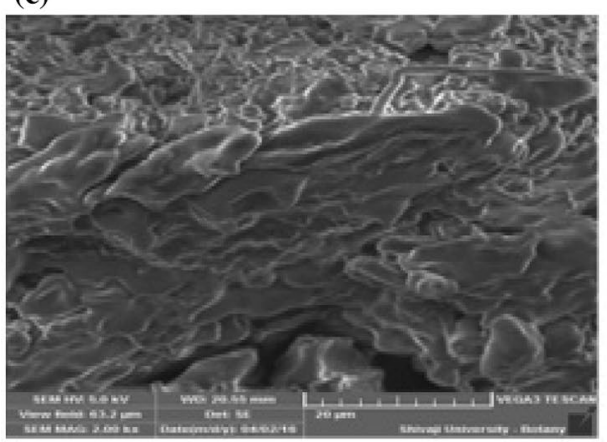

(b)

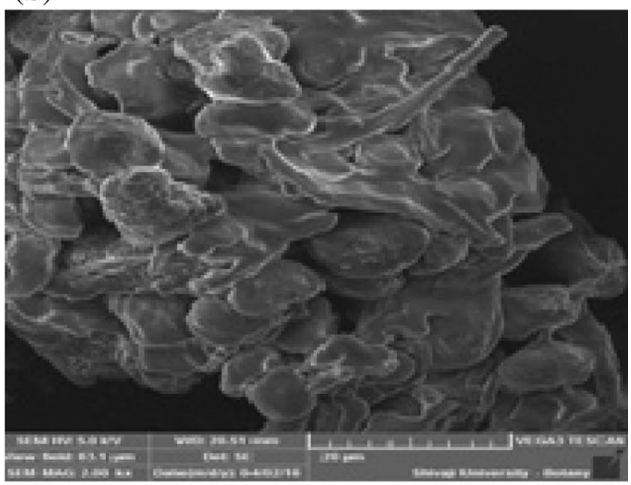

(d)

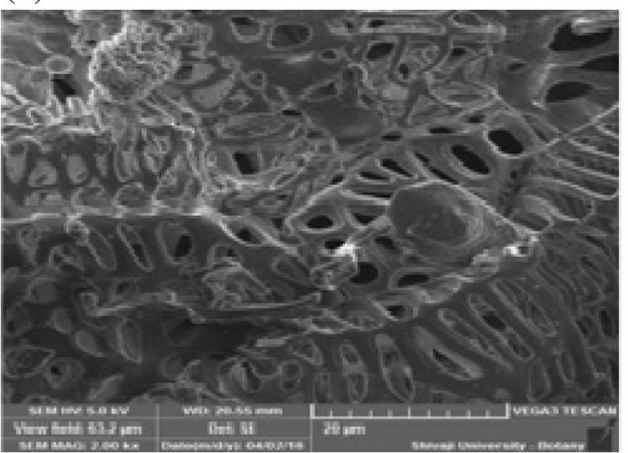


relatively more porous compared to these two. Coat is highly porous with reticulated structure providing lesser sites for adsorption.

Further, the time required for drying of pods and its rate also plays a significant role in inducing quality ingredient (protein structure) and surface morphology of seed kernel. Sun-dried and oven-dried were subjected to 1 week and $2 \mathrm{~h}$ of drying time, respectively. Complete drying of pods in the tree naturally takes larger time and drying occurs gradually.

This surface morphology study and coagulation study reveal that naturally dried Moringa oleifera seed kernel has greater potential for turbidity removal. Hence, further study is carried out using naturally dried Moringa oleifera seed kernel.

\section{Effect of Strength of Moringa oleifera and Strychnos potatorum extract on turbidity removal}

The effect of varied strengths of Moringa oleifera extract was studied using $0.5,1,5,10$ and $15 \%$ extracts, for water sample of $26 \mathrm{NTU}$ turbidity, and $100 \mathrm{mg} / \mathrm{L}$ dose of Moringa oleifera. Figure 3a shows the effect of Moringa oleifera strength on turbidity removal. It can be observed that although removal increases with increase in strength from 0.5 to $15 \%$, the increase is not significant beyond $1 \%$. Hence, $1 \%$ strength resulting in $88 \%$ removal was used for the further study. Figure $3 \mathrm{~b}$ shows the turbidity removal with strength 1, 3, 5 and $8 \%$ of Aloe Vera for initial turbidity 32 NTU and Aloe Vera dose of $50 \mathrm{mg} / \mathrm{L}$. It can be observed that Aloe Vera as a coagulant is not effective for turbidity removal. However, $1 \%$ strength is appropriate for Aloe Vera application as coagulant/coagulant aid. In case of Strychnos potatorum seeds, initial study for deciding dose range revealed that dose of $0.1-1 \mathrm{mg} / \mathrm{L}$ is sufficient for optimum turbidity removal. An extract of $0.1 \%$ was used considering the practical consideration of dose application. As lower dose application with higher strength extracts is not practicable, the strength effect study is not advisable for Strychnos potatorum seed extract.

\section{Turbidity removal with Moringa oleifera and Strychnos potatorum seeds}

Figure 4 shows the residual turbidity after applying varied dose of naturally dried seed kernel of Moringa oleifera for low, medium and high turbid water. It can be observed that for low turbidity water residual turbidity increases with added dose of Moringa oleifera. The colloidal and suspended solids concentration is less for low turbidity water, excess dose results in increase in residual turbidity due to uncombined coagulant, as sufficient particles are not available to combine with coagulant protein. The optimum dose
Fig. 3 Effect of strength of a Moringa oleifera extract and $\mathbf{b}$ Aloe Vera extract on turbidity removal (a)

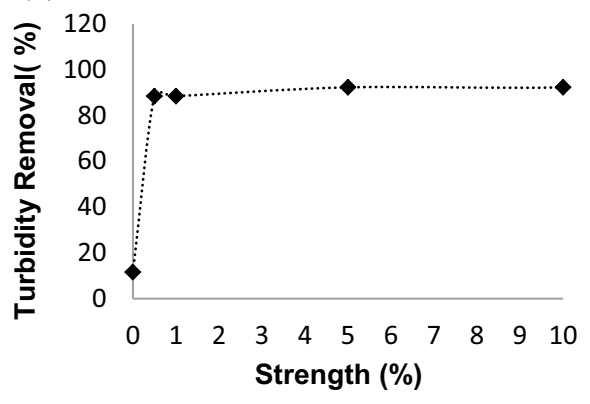

(b)

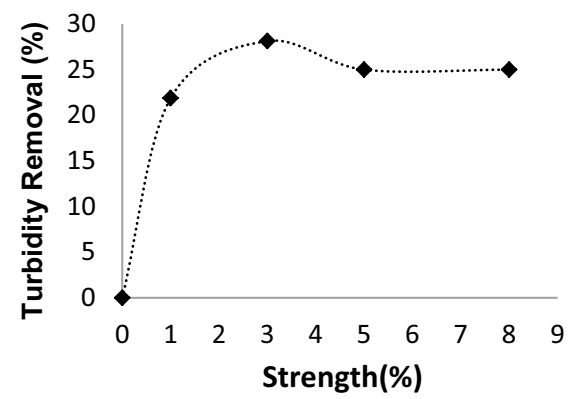

Fig. 4 Turbidity removal by naturally dried Moringa oleifera seed in (1) low, (2) medium and (3) high turbidity water

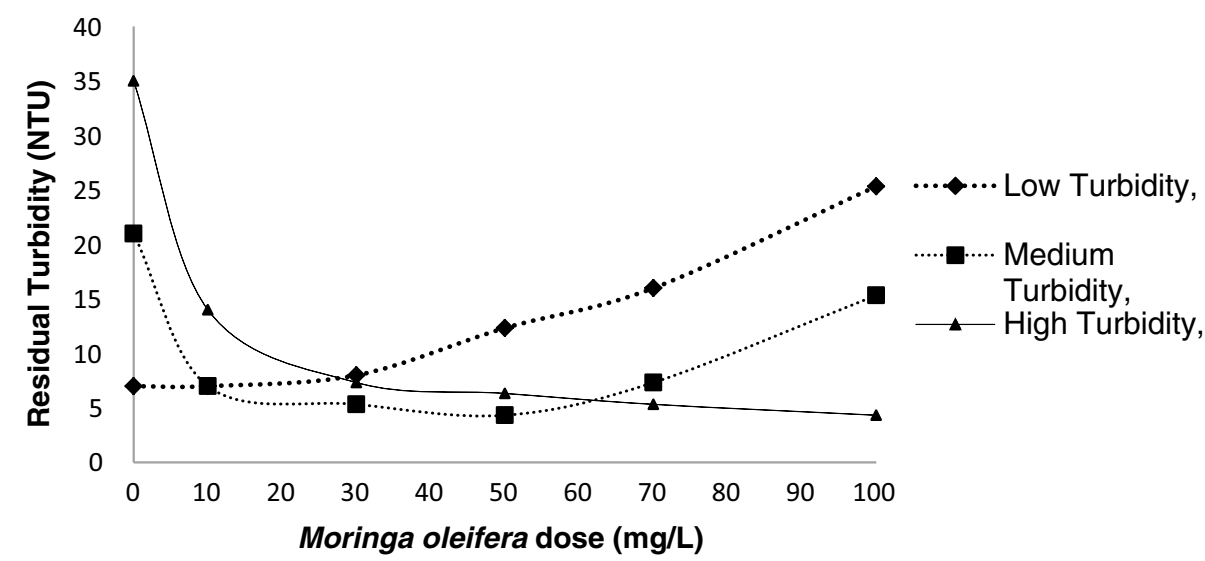


for medium and high turbidity samples was observed to be 50 and $100 \mathrm{mg} / \mathrm{L}$, respectively, with turbidity removal efficiency of 80.95 and $88.57 \%$. This indicates that coagulant dose required increases with initial turbidity for medium and high turbidity water, as more charged sites are necessary for adsorption and chemical bridging. After optimum dose the residual turbidity increases with added dose of coagulant, because of non-availability of sufficient number of particles for bridging with the charged sites of coagulant and turbidity increases due to suspended coagulant matter.

Figure 5 shows the effect of varied dose of Strychnos potatorum on turbidity removal for low, medium and high turbid water. The results show that the removal efficiency increases from high to low turbidity water and for maximum removal optimum dose was observed to be $0.8,0.6$ and $0.2 \mathrm{mg} / \mathrm{L}$ for high, medium and low turbidity water, respectively. Thereafter, residual turbidity increases insignificantly. The turbidity removal for low, medium and high turbidity samples was $71.42,64.28$ and $57.14 \%$, respectively.

This study reveals that Moringa oleifera is not effective for low turbidity water, but Strychnos potatorum seeds show good results. For medium, Moringa oleifera is more effective coagulant for high turbidity water, as compared to Strychnos potatorum.

\section{Effect of Aloe Vera as coagulant aid and as polymer with ballasting agents in turbidity removal}

The efforts were taken to improve the efficiency of coagulation process by using Aloe Vera as a natural coagulant aid with Moringa oleifera and Strychnos potatorum as natural coagulants. Table 1 shows the comparison of optimum dosage of Moringa oleifera, when used with and without Aloe Vera. The results show that Aloe Vera is more effective as coagulant aid when used with Moringa oleifera for low turbidity water and relatively less effective for medium and high turbidity water. Aloe Vera acts as a polymer which possesses charged sites, to which micro-flocs formed with Moringa oleifera get attached, and large settleable flocs are formed.

This table also gives the optimum combination of Moringa oleifera, Aloe Vera and micro-sand for turbidity removal. It can be seen that the use of ballasting agent (micro-sand) with Aloe Vera has enhanced the turbidity removal. The dosage of Moringa oleifera is also reduced for medium and high turbidity water. This is due to improved settling conditions with increase in weight of flocs. Addition of polymer leads to branched floc formation and sand provides surface area for floc formation. The micro-flocs formed lead to the formation of macro-flocs by attaching with micro-sand. The physical attachment and enmeshment followed by fast settling macro-flocs are the causes of enhanced turbidity removal.
Fig. 5 Turbidity removal by Strychnos potatorum seed in (1) low, (2) medium and (3) high turbidity water

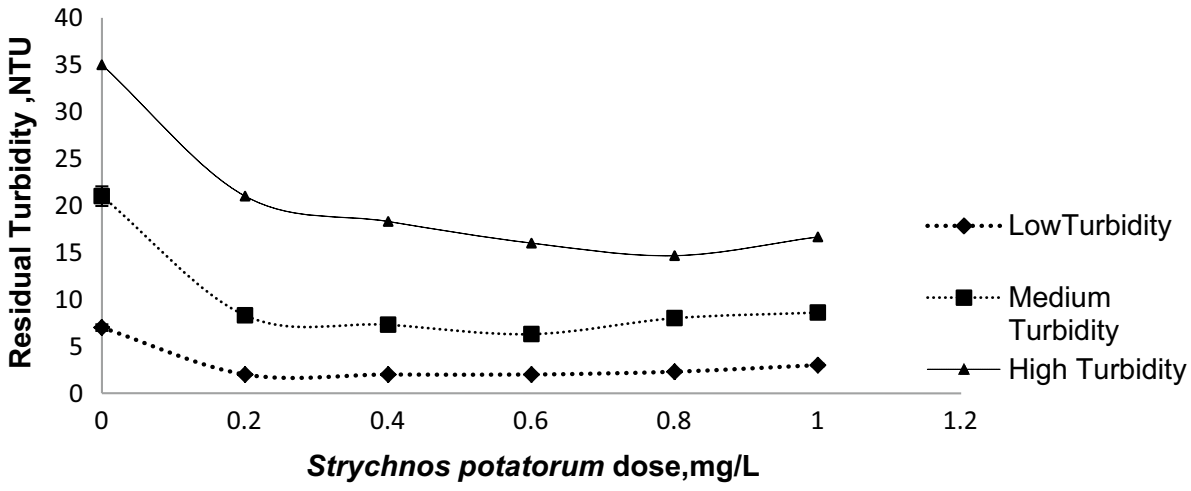

Table 1 Turbidity removal by Moringa oleifera $(M O)$ with and without Aloe Vera $(A V)$; ballasted coagulation by $M O, A V$, and micro-sand

\begin{tabular}{|c|c|c|c|c|c|c|c|c|c|}
\hline \multirow[t]{3}{*}{ Initial turbidity } & \multicolumn{2}{|l|}{$M O$} & \multicolumn{3}{|c|}{$M O+A V$} & \multicolumn{4}{|c|}{$M O+A V+$ micro-sand } \\
\hline & \multirow[t]{2}{*}{$\begin{array}{l}\text { Optimum } \\
\text { dose }(\mathrm{mg} / \mathrm{L})\end{array}$} & \multirow[t]{2}{*}{$\begin{array}{l}\text { Res. turbid- } \\
\text { ity (NTU) }\end{array}$} & \multicolumn{2}{|c|}{$\begin{array}{l}\text { Optimum } \\
\text { dose }(\mathrm{mg} / \mathrm{L})\end{array}$} & \multirow[t]{2}{*}{$\begin{array}{l}\text { Residual tur- } \\
\text { bidity (NTU) }\end{array}$} & \multicolumn{3}{|c|}{ Optimum dose } & \multirow{2}{*}{$\begin{array}{l}\text { Residual } \\
\text { turbidity } \\
\text { (NTU) }\end{array}$} \\
\hline & & & MO & AV & & $\mathrm{MO}(\mathrm{mg} / \mathrm{L})$ & $\mathrm{AV}(\mathrm{mg} / \mathrm{L})$ & $\begin{array}{l}\text { micro-sand } \\
(\mathrm{g} / \mathrm{L})\end{array}$ & \\
\hline Low (7NTU) & 10 & 7 & 10 & 10 & 4 & 10 & 10 & 0.5 & 3 \\
\hline Medium (21NTU) & 50 & 4 & 50 & 10 & 3 & 30 & 10 & 1 & 2 \\
\hline High (35NTU) & 100 & 4 & 100 & 10 & 3 & 70 & 10 & 1 & 2 \\
\hline
\end{tabular}


Table 2 shows the comparison of optimum dosages of Strychnos potatorum with and without $A V$. The combination of Strychnos potatorum and $A V$ did not give good results as compared with $M O$ and $A V$. This may be due to $A V$, which bridges with some of the charged sites on coagulant protein, making them unavailable to the colloidal particles. At higher concentration of colloidal and suspended matter, the removal is more due to greater opportunity for contact to form large and readily settleable flocs. This table also shows that the use of micro-sand and $A V$ as polymer with Strychnos potatorum improves turbidity removal for medium and high turbidity water, as compared with Strychnos potatorum alone. Although removal improves by this combination, post-treatment is necessary to reduce the turbidity below 1 NTU.
Table 3 shows the results of ballasted coagulation with $M O, A V$ and powdered activated carbon (PAC). It can be seen that the use of PAC as ballasting agent with $M O$ and $A V$ has resulted in residual turbidity of 1 NTU or below 1 NTU for all types of turbid water. The larger surface area and surface texture of PAC particles, coating with Aloe Vera, formation of micro-flocs induced by $M O$ with nucleus of PAC, and adsorption of colloidal particles contribute to improved turbidity removal. The results of ballasted coagulation by $S P, A V$ and PAC given in Table 1 show enhanced turbidity removal but resulting residual turbidity is 2 NTU or below 2 NTU.

Table 2 Turbidity removal by Strychnos potatorum (SP) with and without $A V$; and ballasted coagulation by $S P, A V$, and micro-sand

\begin{tabular}{|c|c|c|c|c|c|c|c|c|c|}
\hline \multirow[t]{3}{*}{ Initial turbidity } & \multicolumn{2}{|l|}{$S P$} & \multicolumn{3}{|c|}{$S P+A V$} & \multicolumn{4}{|c|}{$S P+A V+$ micro-sand } \\
\hline & \multirow[t]{2}{*}{$\begin{array}{l}\text { Optimum } \\
\text { dose }(m g / L)\end{array}$} & \multirow[t]{2}{*}{$\begin{array}{l}\text { Residual tur- } \\
\text { bidity, NTU }\end{array}$} & \multicolumn{2}{|c|}{$\begin{array}{l}\text { Optimum } \\
\text { dose }(m g / L)\end{array}$} & \multirow[t]{2}{*}{$\begin{array}{l}\text { Residual tur- } \\
\text { bidity, NTU }\end{array}$} & \multicolumn{3}{|c|}{ Optimum dose } & \multirow{2}{*}{$\begin{array}{l}\text { Residual } \\
\text { Turbidity, } \\
\text { NTU }\end{array}$} \\
\hline & & & $S P$ & $A V$ & & $S P(\mathrm{mg} / \mathrm{L})$ & $A V(\mathrm{mg} / \mathrm{L})$ & $\begin{array}{l}\text { Micro-sand } \\
(\mathrm{g} / \mathrm{L})\end{array}$ & \\
\hline Low (7NTU) & 0.2 & 2 & 0.2 & 10 & 5 & 0.4 & 40 & 1 & 3 \\
\hline Medium (21NTU) & 0.6 & 6 & 0.6 & 10 & 11 & 1 & 50 & 0.8 & 3 \\
\hline High (35NTU) & 0.8 & 15 & 0.8 & 20 & 7 & 0.6 & 10 & 0.6 & 2 \\
\hline
\end{tabular}

Table 3 Turbidity removal by $M O, A V$ and PAC; and $S P, A V$ and PAC

\begin{tabular}{|c|c|c|c|c|c|c|c|c|}
\hline \multirow[t]{3}{*}{ Initial turbidity, NTU } & \multicolumn{4}{|c|}{$M O+A V+P A C$} & \multicolumn{4}{|c|}{$S P+A V+P A C$} \\
\hline & \multicolumn{3}{|c|}{ Optimum dose } & \multirow{2}{*}{$\begin{array}{l}\text { Res. turbid- } \\
\text { ity, NTU }\end{array}$} & \multicolumn{3}{|c|}{ Optimum dose } & \multirow{2}{*}{$\begin{array}{l}\text { Residual } \\
\text { turbidity, } \\
\text { NTU }\end{array}$} \\
\hline & $M O(\mathrm{mg} / \mathrm{L})$ & $A V(\mathrm{mg} / \mathrm{L})$ & $\operatorname{PAC}(\mathrm{g} / \mathrm{L})$ & & $S P(\mathrm{mg} / \mathrm{L})$ & $A V(\mathrm{mg} / \mathrm{L})$ & PAC (g/L) & \\
\hline Low (7NTU) & 30 & 70 & 0.5 & 0 & 0.4 & 40 & 0.5 & 1 \\
\hline Medium (21NTU) & 70 & 30 & 0.5 & 0 & 0.4 & 10 & 0.2 & 2 \\
\hline High (35NTU) & 100 & 30 & 0.1 & 1 & 0.2 & 50 & 0.5 & 1 \\
\hline
\end{tabular}

Fig. 6 Effect on settling time by use of $\mathbf{a} M O, \mathbf{b} S P$ with and without micro-sand and PAC
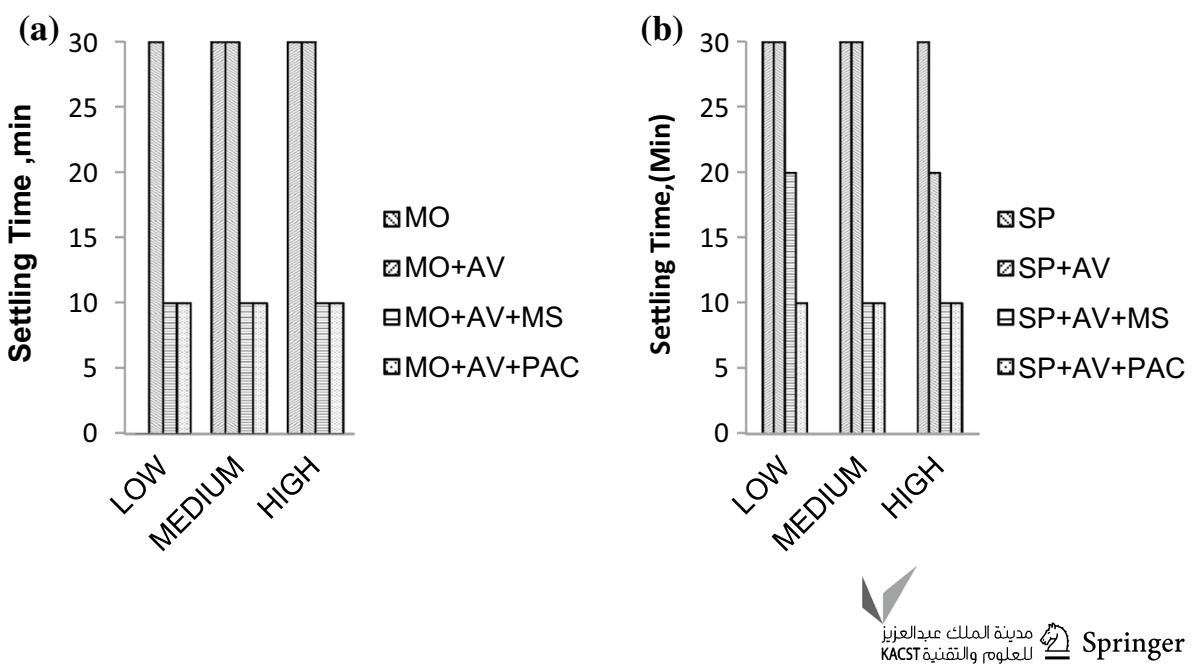


\section{Effect on settling time in ballasted coagulation}

Figure 6 shows the effect on settling time in ballasted coagulation with micro-sand and PAC. The residual turbidity was measured after coagulation-flocculation for 10,20 and 30 min of settling. It can be observed that the use of ballasting agents micro-sand or PAC reduces settling time from 30 to 10 min for obtaining residual turbidity below 4 NTU, as compared with $M O$, and $M O+A V$ for all three categories of turbid water. Dose of $M O$ increased the residual turbidity for low turbidity water, hence the effect on settling time was not considered.

Figure 6 also shows that the use of micro-sand and PAC reduces settling time to $20 \mathrm{~min}$, and $10 \mathrm{~min}$, respectively, for low turbidity water to reduce residual turbidity to 3 NTU. The settling time was reduced to $10 \mathrm{~min}$ for medium and high turbidity water by both micro-sand and PAC for obtaining residual turbidity of 6 NTU. Settling time was observed to be 30 min without the use of ballasting agents.

Addition of polymer in treatment leads to branched floc formation and addition of sand/PAC increases weight of the flocculated particles leading to faster settling of suspended solids. The polymer binds the sand/PAC to the floc, thereby avoiding dispersed floc. The reduction in settling time is significant as high-rate clarifiers such as tube/plate/lamella settlers can be used in separation.

\section{Effect of Aloe Vera on dosages of MO and SP in ballasted coagulation}

Figure 7a shows reduction in $M O$ dose, with $A V$ and ballasting agents. It can be seen that the dose of $M O$ was reduced to $30 \mathrm{mg} / \mathrm{L}, 10 \mathrm{mg} / \mathrm{L}$ and $10 \mathrm{mg} / \mathrm{L}$ for high, medium and low turbidity water for obtaining residual turbidity of 4 NTU, respectively. The dose reduction is due to improved coagulation, flocculation and settling of particles, with the aid of polymer and ballasting agents.

Figure $7 \mathrm{~b}$ shows reduction in $S P$ dose, when used in combination with $A V$ and ballasting agents to reduce the residual turbidity below 4 NTU. The ballasting agents are effective with coagulant and polymer, even for low turbidity water. The study shows that ballasting agents reduce the time and quantity of coagulant required for water treatment.

\section{Conclusions}

1. The coagulation study with various forms of kernel and parts of Moringa oleifera seed revealed that the naturally dried Moringa oleifera seed kernel has more potential for turbidity removal, with removal efficiency of $88.57 \%$, when compared with sun-dried and ovendried seed kernel and coat with removal efficiencies as 58,48 and $36 \%$, respectively.

2. The study on effect of naturally dried Moringa oleifera seed extract strength revealed that $1 \%$ extract gives $88 \%$ turbidity removal. Strength of $1 \%$ Aloe Vera leaf pulp solution was found to be more effective for turbidity removal; however, the study revealed that Aloe Vera is not an effective coagulant.

3. Moringa oleifera is not effective for low turbidity water, but it is effective for medium and high turbidity water. The optimum dose of Moringa oleifera for medium and high turbidity water was 50 and $100 \mathrm{mg} / \mathrm{L}$, respectively, with turbidity removal of 80.95 and $88.57 \%$.

4. Strychnos potatorum is effective for low, medium and high turbidity water, although the removal efficiency is less as compared with Moringa oleifera for medium and high turbidity water. The optimum dose of Strychnos potatorum for low, medium and high turbidity water was $0.2,0.6$, and $0.8 \mathrm{mg} / \mathrm{L}$, respectively, with turbidity removal as $71.42,64.28$ and $57.14 \%$.

5. Aloe Vera acts as a coagulant aid with Moringa oleifera and is effective for low turbidity water with removal up to $40 \%$; however, its effect is lesser for medium and high turbidity water.

6. The ballasted coagulation with Moringa oleifera/Strychnos potatorum, micro-sand and Aloe Vera increases turbidity removal by $5-10 \%$ when compared to conventional coagulation with Moringa oleifera.
Fig. 7 Effect of $A V$ and ballasting agents on dose of a $M O$, and $\mathbf{b} S P$

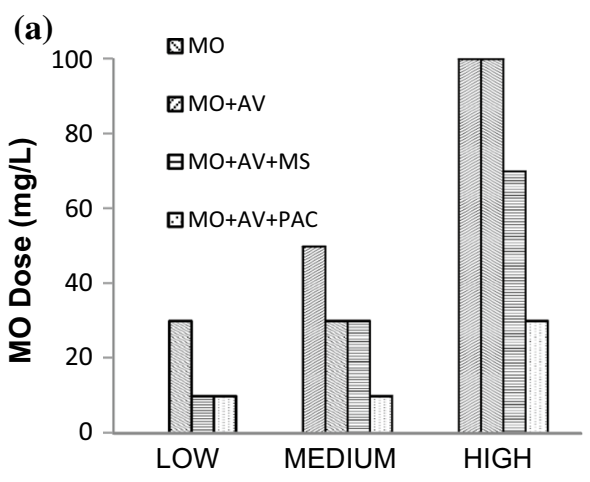

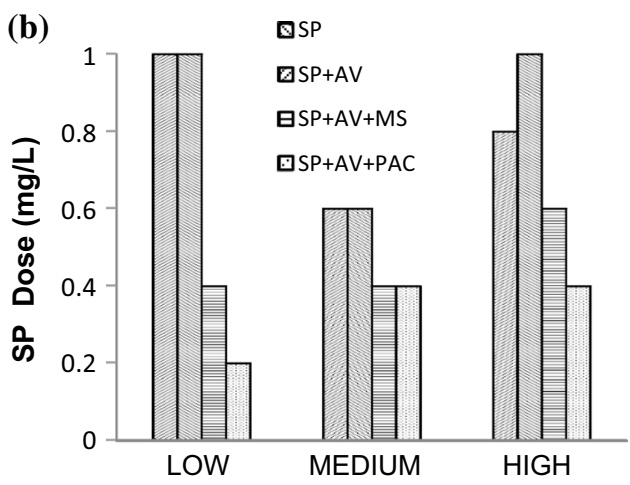

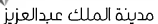

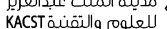


7. The use of PAC as ballasting agent and Aloe Vera as natural polymer, with the coagulant Moringa oleifera, or Strychnos potatorum is most effective in reducing the turbidity of low, medium and high turbidity water samples below 1 NTU.

8. The use of ballasting agent as micro-sand or PAC reduces the settling time required for settling of flocs, by increasing the weight of flocs. The reduction in settling time is by $10-20 \mathrm{~min}$. The ballasting agents reduce the coagulant dose by $20-70 \mathrm{mg} / \mathrm{L}$ with Moringa oleifera and 0.2-0.6 with Strychnos potatorum.

9. The study revealed that the coagulation with Moringa oleifera and Strychnos potatorum is a cost-effective alternative, particularly for rural area. The ballasting agents reduce the quantity of coagulant and time required for water treatment.

Acknowledgements We the authors would like to thank The Principal, PVPIT, and The Director, Walchand College of Engineering, Sangli, for providing necessary facilities and guidance for our research work.

\section{Compliance with ethical standards}

Conflict of interest The authors declare that they have no conflict of interest.

Open Access This article is distributed under the terms of the Creative Commons Attribution 4.0 International License (http://creativeco mmons.org/licenses/by/4.0/), which permits unrestricted use, distribution, and reproduction in any medium, provided you give appropriate credit to the original author(s) and the source, provide a link to the Creative Commons license, and indicate if changes were made.

\section{References}

Ali RM, Hamad HA, Hussein MM, Malash GF (2016) Potential of using green adsorbent of heavy metal removal from aqueous solutions: adsorption kinetics, isotherm, thermodynamic, mechanism and economic analysis. Ecol Eng 91:317-332

Bell-Ajy K, Abbaszadegan M, Ibrahim E, Verges D, LeChevallier M (2000) Conventional and optimized coagulation for NOM removal. J Am Water Works Assoc 92:44-57

Bhole AG, Shrivastava DR (1983) Relative evaluation of a few natural coagulants. J Indian Water Works Assoc 15:270-275
Blumenschein CD, Latker E, Banerjee K (2004) Sand ballasted high rate clarification process for treatment of process water. Int Water Center 6:20

Dalen MB, Pam JS, Izang A, Ekel R (2011) Synergy between Moringa oleifera seed powder and alum in the purification of domestic waste water. Sci World J 4:6-11

Ghanem AV, Young JC, Edwards FG (2007) Mechanisms of ballasted flocculation. J Environ Eng Am Soc Civ Eng 133(3):271-277

Gulmire A, Munavalli GR (2017) Use of aloe vera as coagulant aid in turbidity removal. Int J Eng Res Technol 10(1):314-317

Jahn SAA (1986) Using Moringa seeds as coagulants in developing countries. J Am Water Work Assoc 80(6):43-50

Joseane DPT, Guilherme FL, Ricardo FZ (2013) Coagulant and natural polymer: perspective for treatment of water. Plast Polym Technol 2(3):55-62

Montakhab A, Gazali BT (2010) Effects of drying and salt extraction of Moringa oleifera on its coagulation of high turbid water. J Am Sci 6(10):387-392

Muyibi SA, Evison LM (1995) Optimizing physical parameters affecting coagulation of turbid water with Moringa oleifera seeds. Water Res 29(12):2689-2695

Narasiah KS, Vogel A, Kramadhati NN (2002) Coagulation of turbid waters using Moringa oleifera seeds from two distinct sources. Water Sci Technol Water Supply 2(5-6):83-88

Okuda T, Baes AU, Nishijima W, Okuda M (2001) Coagulation mechanism of salt solution-extracted active component in Moringa oleifera seeds. Water Res 35(3):830-834

Raghuwanshi P, Mandloi M, Sharma AJ, Malviya HS, Chaudhari S (2002) Improving filtrate quality using agro based materials as coagulant aid. Water Qual Res J 37(4):745-756

Sarpong G, Richerdson CP (2010) Coagulation efficiency of Moringa oleifera for removal of turbidity and reduction of total coliform as compared to aluminium sulfate. Afr J Agric Res 5(21):2939-2944

Shahnwaz S, Gary A, Christian D, Jerome L, Chandra M (2002) American Water Works Association-Water quality technology conference

Standard Methods for the Examinations of Water and Wastewater (1998) 20th edn. American Public Health Association/American Water Works Association/Water Environment Federation, Washington DC, USA

Sudhirkumar P, Mishra D, Ghosh G, Panda CD (2010) Medicinal uses and pharmacological properties of Moringa oleifera. Int J Phytomed 2:210-216

Swati M, Govindan VS (2005) Coagulation studies on natural seed extracts. J Indian Water Assoc 33(5):145-152

Young JC, Edwards FG (2003) Factors affecting ballasted flocculation reactions. Water Environ Res 75(3):263-272

Publisher's Note Springer Nature remains neutral with regard to jurisdictional claims in published maps and institutional affiliations. 